\title{
IMPLEMENTASI PENERAPAN METODE WATERFALL PADA APLIKASI SISTEM INFORMASI TV KABEL ONLINE DAN MOBILE
}

\author{
Jauhari Maulani ${ }^{1)}$ Muhammad Amin ${ }^{2)}$, dan Galih Mahalisa ${ }^{3)}$ \\ Fakultas Teknologi Informasi, Universitas Islam Kalimantan Muhammad Arsyad Al Banjari Banjarmasin \\ Fakultas Teknologi Informasi, Universitas Islam Kalimantan Muhammad Arsyad Al Banjari Banjarmasin \\ Fakultas Teknologi Informasi, Universitas Islam Kalimantan Muhammad Arsyad Al Banjari Banjarmasin \\ Email : \\ jauharimaulani@gmail.com ${ }^{1}$, \\ maminbjm58@gmail.com ${ }^{2}$, \\ galih.mahalisa@gmail.com ${ }^{3)}$
}

\begin{abstract}
Abstrak
Perusahaan tv kabel banyak menawarkan jasa pemasangan paket program tv kabel berlangganan, namun para pelanggan mencari informasi seperti apa kualitas provider, pemasangan berlangganan tv kabel serta pengaduannya, hanya melalui informasi yang didapat dari brosur, tetapi brousur saja tidak cukup maka dibuatlah informasi online agar informasi dapat dilihat tidak terkendala jarak dan waktu. Pembuatan aplikasi tv kabel online di implementasikan dengan menggunakan metode waterfall, yang mana dari permasalahan yang ada di perusahaan tv kabel terus di analisis dan dibuat rancangan dengan orientasi objek hingga di implementasikan menjadi sebuah aplikasi online yang dapat dijalankan di browser web dan mobile android atau ios. Adanya aplikasi ini dapat langsung berlangganan dengan pendaftaran online juga dapat melihat informasi atau promo tv kabel yang tersedia dan pengaduan permasalahan tv kabel.
\end{abstract}

Kata Kunci: Aplikasi Online, Mobile, TV Kabel, Waterfall

\section{PENDAhuluan}

Seperti Kita Ketahui banyak perusahaanperuaahaan yang menawarkan jasa Pemasangan Program TV berlangganan yang tersebar dimana manaadanya persaingan layanan provider $\mathrm{Tv}$ berlangganan, ada baiknya Calon pelanggan mencari tahu seperti apa kualitas dari provider penyedia tv kabel berlangganan dari kualitas gambar hingga layanan, Bagaimana caranya? ini cukup sederhana, pelanggan bisa mencari referensi dari teman atau orang disekeliling atau disekitarnya atau di media sosial atau web TV berlangganan yang bersangkutan akan tetapi bagi penyelenggara banyak tidak menyediakan Pendftaran Online yang dapat mempermudah bagi calon pelanggan untuk mendaftar jadi anggota secara online [1] .

Berdasarkan latar belakang tersebut dapat dirumuskan masalahnya adalah membuat Implementasi Penerapan Metode Waterfall pada Aplikasi Pendaftaran TV Kabel Online dan Mobile, agar segala macam informasi dapat terintegrasi dengan baik, dan juga sumber informasi dapat diskses oleh siapa saja, dimana saja dan terkelola dengan baik. [2]

Tujuan dari penelitian ini adalah untuk menjadikan sebuah Aplikasi berbasis online dan mobile yang dapat menjakau segala informasi yang terbuka, baik bagi user terdaftar maupun bagi user umum, agar dapat dengan mudah mengakses dan mencari informasi dimana saja

manfaat yang didapatkan dari Implementasi Penerapan Metode Waterfall pada Aplikasi Pendaftaran TV Kabel Online dan Mobile ini, bagi masyarakat dapat menggunakan aplikasi online sebagai alternative utuk pendaftaran dan mengetahui Promo dan layananan Pelanggan, Bagi peneliti untuk menambah penerapan Bahasa program PHP dan penerapan online dan mobile baik di komputer maupun di Handphone baik Android maupun IOS dari Apple.

Dalam suatu penetian diperlukan dukungan hasil-hasil penetian yang telah ada 
sebelumnya yang berkiatan dengan penetian tersebut.

Peneltian menurut Nurul Fajrina Yusran yaitu Bisnis pertelevisian TV Kabel sangat marak di Indonesia. Hampir semua provinsi di negeri ini sudah ada perusahaan Televisi Kabel. Televisi Kabel saat ini telah berkembang pesat menjadi usaha industri yang handal, menjadi penopang dalam bagian perkembangan industri pertelevisian. Dari banyaknya perusahaan TV Kabel saat ini yang tersebar di penjuru seluruh Indonesia, salah satunya yaitu CV.Matahari merupakan perusahaan yang bergerak di bidang industri pertelevisian, yang bisa menangani beberapa kebutuhan pelanggan, seperti transaksi pendaftaran, pembayaran, pelaporan atau pengaduan, namun yang sifatnya masih manual. Sehingga mempersulit atau memperlambat kerja pegawai dalam mencari data pelanggan. Olehnya itu diperlukan suatu sistem yang dapat membantu kinerja para pegawai. Penelitian ini menerapkan metode penelitian kualitatif dilakukan dengan pendekatan penelitian saintifik sedang metode pengumpulan data yang digunakan yaitu wawancara, studi pustaka dan studi literatur. Adapun metode pengujian penelitian yang digunakan adalah Blakckbox. Dimana Blackbox mengamati hasil uji eksekusi melalui data uji dan fungsional dari perangkat lunak, mengevaluasi hanya pada tampilannya saja. Hasil penelitian ini berupa suatu sistem informasi atau aplikasi pelayanan terhadap pelanggan. Sistem informasi ini dapat membantu meningkatkan kinerja karyawan dalam pelayanan pada pelanggan serta menghasilkan suatu keputusan yang berkualitas baik [3].

\section{METODE PENELITIAN}

Siklus Pengembengan Sistem Informasi atau System Development Life Cycle (SDLC) yang identik dengan istilah metode air terjun (Waterfall Method) [4]

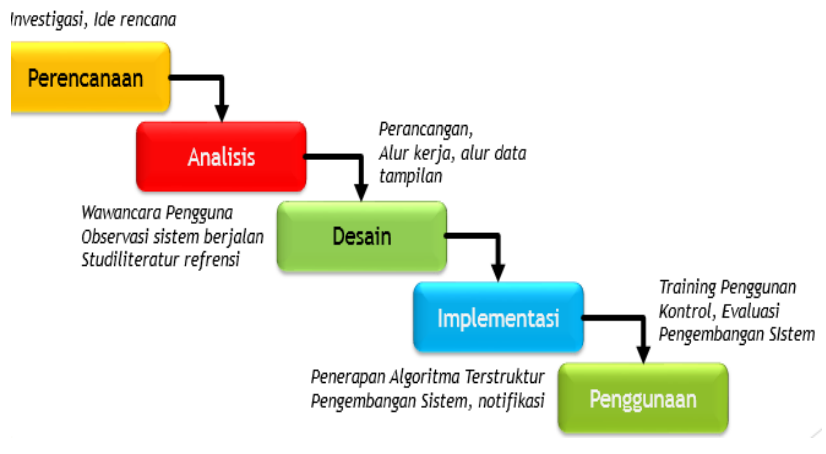

Gambar 1. Tahapan Metode Air Terjun (Waterfall Method)

\section{Perencanaan Pengembangan Aplikasi}

Dari permasalahan yang ada di perusahaan tv kabel mengenai jasa pemasangan paket program tv kabel berlangganan maka dirancang perencanaan sebuah sistem informasi online, agar informasi dapat dilihat tidak terkendala jarak dan waktu

\section{Analisis Pengumpulan Data}

Proses pengumpulan data dilakukan dengan 2 cara yaitu :

1. Pengumpulan data primer, dengan melakukan survey sesuai dengan kebutuhan data

2. Pengumpulan data sekunder, dikumpulkan dengan mengamati data dan mempelajari data tersebut.

Langkah-langkah yang ditempuh dalam menyelesaikan penelitian sebagai berikut:

1. Studi literatur

Pada tahap studi literatur penulis mencari literatur yang terkait dengan penelitian, sebagai berikut:

a. Mencari referensi mengenai sistem yang terkait.

b. Mencari permasalahan apa yang terjadi pada pengguna kendaraan bermotor pada saat terjadi kerusakan pada saat berada dijalan.

c. Mencari informasi secara lengkap tentang Implementasi Penerapan Aplikasi Pendaftaran TV Kabel Online dan Mobile.

2. Analisis sistem

Pada tahap ini dilakukan analisis masalah sistem yang berjalan, sampai saat ini belum ada aplikasi yang memudahkan dalam pencarian dan informasi secara detail tentang dimana informasi Implementasi Penerapan Aplikasi Pendaftaran TV Kabel Online dan Mobile.

a. Perancangan dan implementasi sistem Di tahap ini dibuatnya percangan sesuai apa yang sudah di analisis dan di lanjutkan dengan implemntasi pembentukan sistem.

b. Pengujian 
melakukan pengujian sistem yang sesuai dengan tujuan dari penelitian.

c. Penyusunan laporan

Tahap ini penulisan atau pembuatan laporan dokumentasi hasil analisis sistem dan implementasi dari sistem dalam bentuk laporan hasil penelitian.

\section{Perancangan Alur Sistem dengan Unified Modeling Language (UML)}

\section{Use Case Diagram Aplikasi}

Uce Case menujukan Akses alur pengembangan Sistem Aplikasi TV Online dari Pelanggan Baru dan Pelanggan dengan admin seperti pada gambar dibawah ini

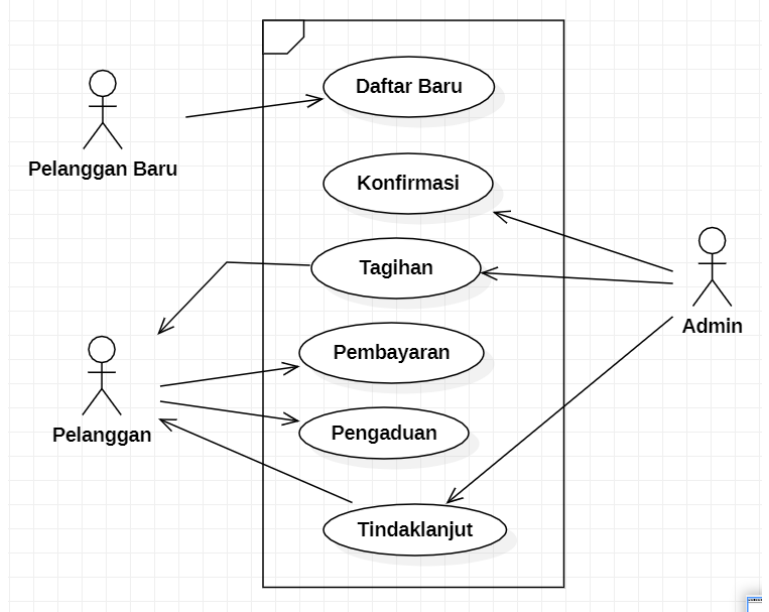

Gambar 2. Use Case Diagram Aplikasi

\section{Diagram Activity}

Dalam diagram Activity pendaftaan pelanggan ini menggambar aktivitas mulai dari pendaftaran Pelanggan baru seperti pada gambar berikut ini

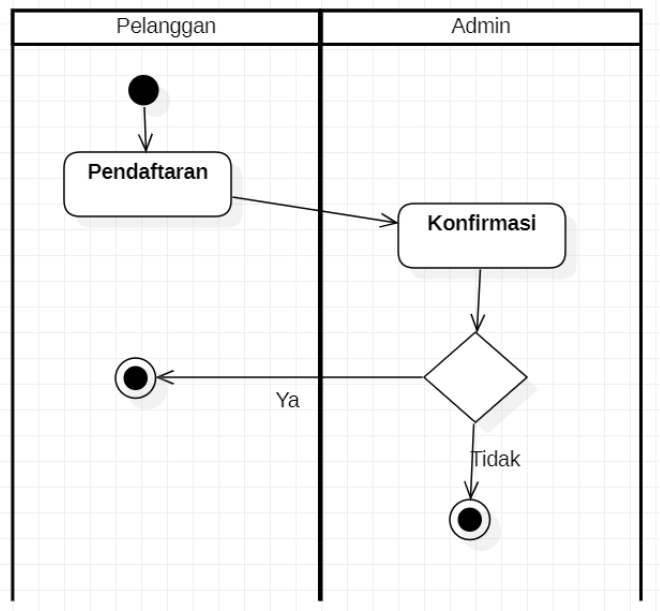

Gambar 3. Activity Diagram Pendaftaran

Diagram Activity Tagihan dan Pembayaran Dalam diagram Activity ini menggambar aktivitas tagihan Pelanggan seperti pada gambar berikut ini.

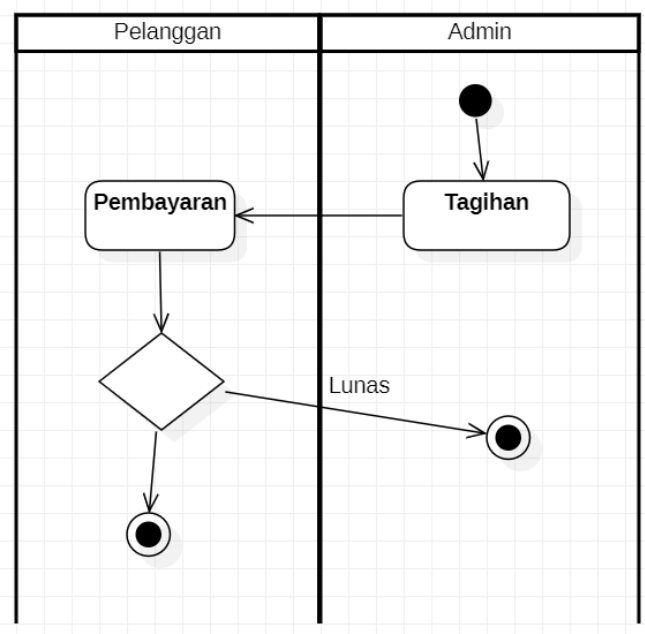

Gambar 4.Activity Diagram Tagihan dan Pembayaran

Diagram Activity Pengaduan Pelanggan Dalam diagram Activity ini menggambar aktivitas Pengaduan Pelanggan seperti pada gambar berikut ini. 


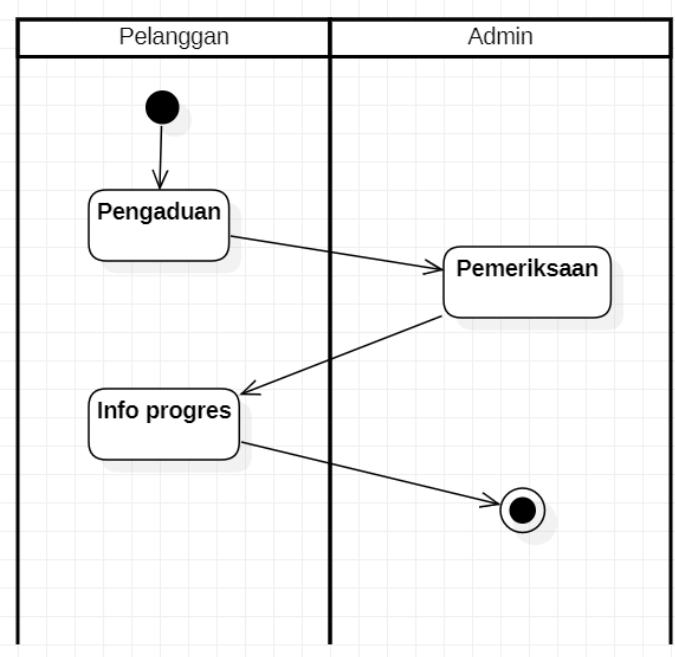

Gambar 5. Actifity Diagram Pengaduan

\section{Sequnce Diagram}

interaksi objek yang diterapkan berdasarkan urutan waktu penggunaan, sequence diagram juga menggambarkan tahapan atau urutan langkah sistem yang harus dilaksanakan untuk dapat menghasilkan tujuan dari sistem seperti, dalam desain berikut ini urutan sequence berikut ini.

Sequnce Diagram Pendaftaran Pelanggan Baru.dalam Sequnce diagram ini pengunjung mendaftar jadi Angota baru di Aplikasi TV online yang tergambar dalam gambar berikut.

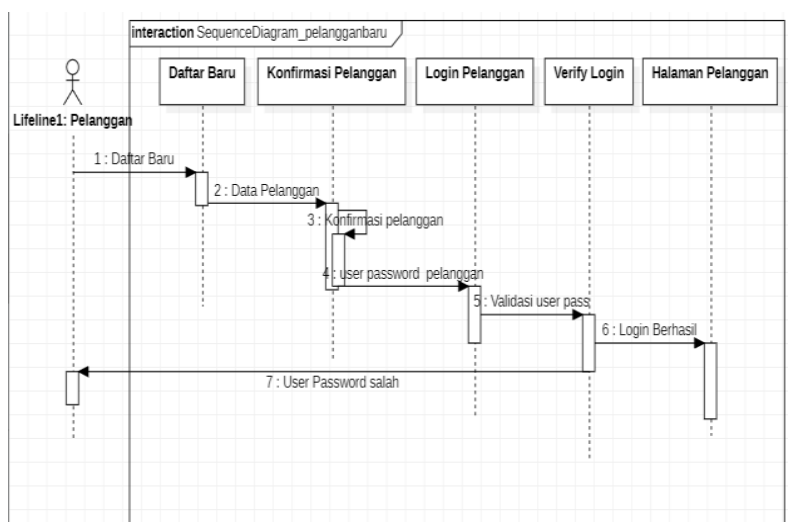

Gambar 6. Sequnce Diagram Pendaftaran

Sequnce Diagram Pengaduan, Dalam Sequnce diagram pengaduan Pelanggan mengadukan permasalahan yang ada pada kegiatan penyaluran siaran TV online yang tergambar dalam gambar berikut ini.

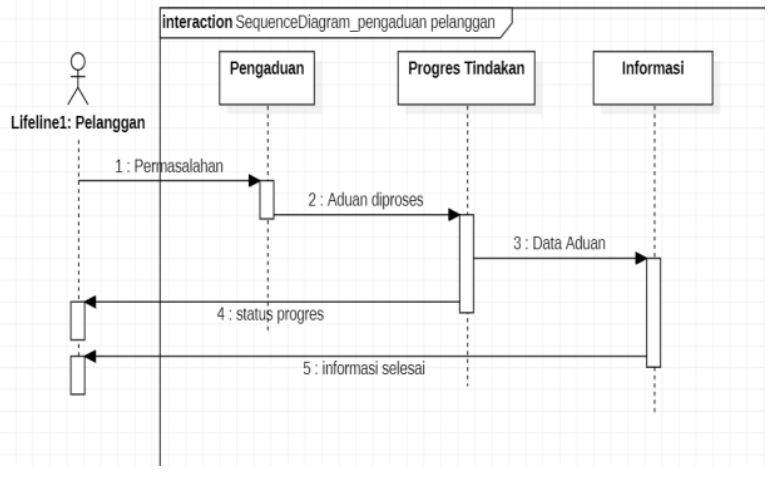

Gambar 7. Sequnce Diagram

Pengaduan

Sequnce Diagram Tagihan Dalam Sequnce diagram Admin membuat Tagihan kepada pelanggan TV online yang tergambar dalam gambar berikut ini.

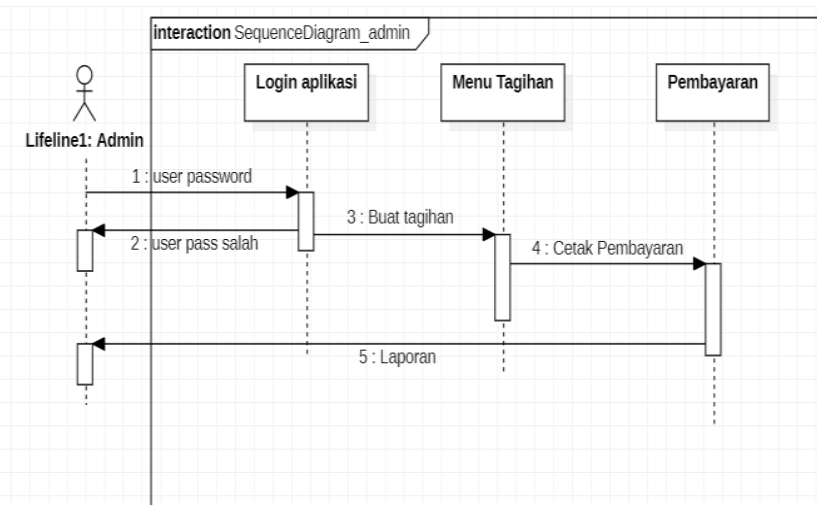

Gambar 8. Sequnce Diagram Penagihan

\section{HASIL DAN PEMBAHASAN}

\section{Implementasi Pengembangan Aplikasi}

Tahapan Implemntasi pengembangan Aplikasi Pendaftaran TV Online dengan permodelan berorentasi Objek setelah dilakukan denan desain Unified Modeling Language (UML), dan sebagai penerapannya sebagai berikut.

Tampilan Muka Web yang bisa dibuka di Windows dan Android 


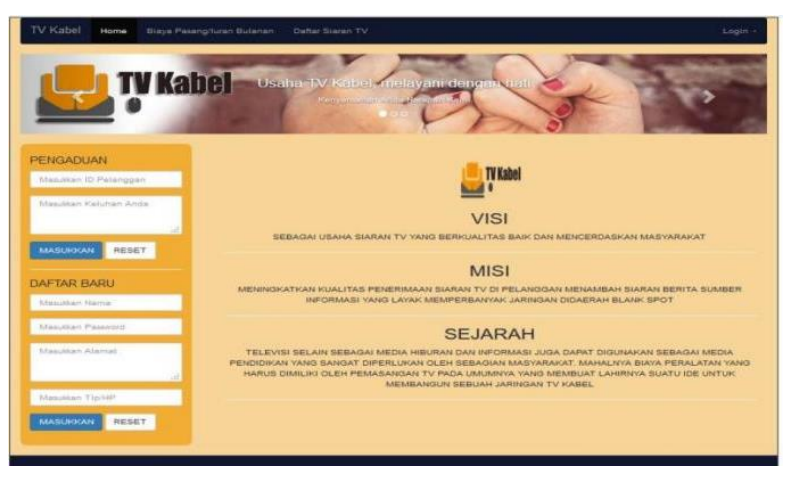

Gambar 9. Tampilan Depan Web

\section{Tampilan Menu Admin}

Dalam Tampilan ini admin bisa Mengkonfirmasi Pelanggan baru, memasukan rekening pembayaran, mengganti Profil, menambah siaran, melihat pengaduan pelanggan dan membuat tagihan.

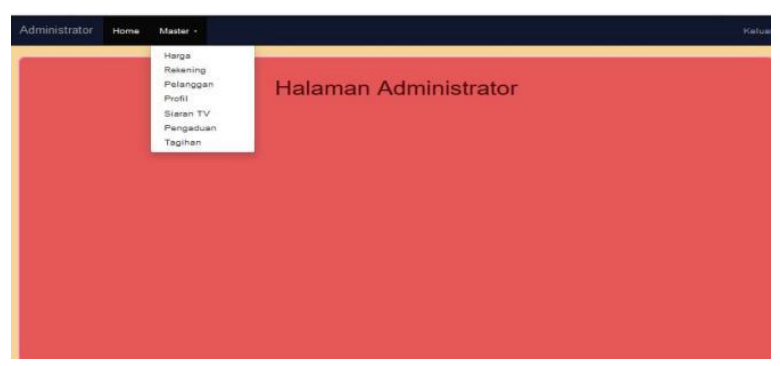

Gambar 10. Login Administrator

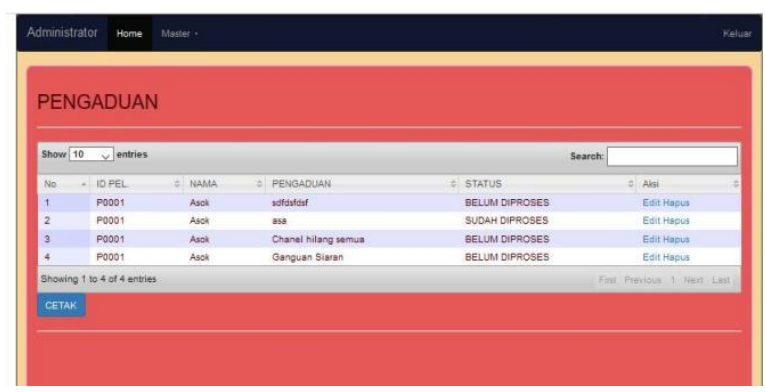

Gambar 11. Data Pengaduan

Tampilan Menu Pelanggan

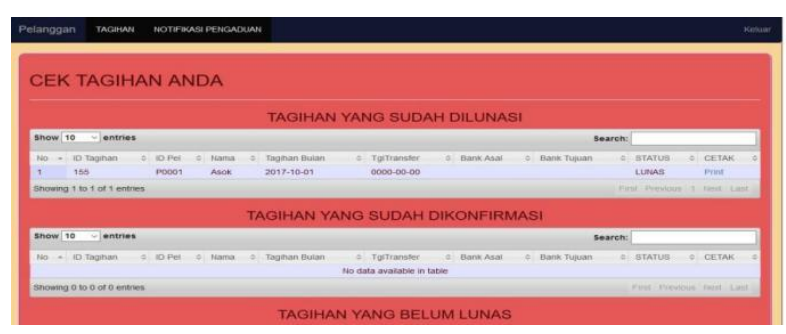

Jurnal Ilmiah “Technologia"

\section{Pengujian dan Penggunaan Aplikasi}

Sebelum aplikasi masuk pada tahap penggunaan pengujian dilakukan terlebih dahulu oleh analis sistem. Pengujian ini dilakukan menggunakan black box testing [5].

Tabel 1. Tabel Pengujian Aplikasi

\begin{tabular}{|c|c|c|c|c|c|}
\hline $\begin{array}{l}\text { Test Case } \\
\text { Description }\end{array}$ & Test Case & $\begin{array}{l}\text { Expected } \\
\text { Result }\end{array}$ & $\begin{array}{l}\text { Actual } \\
\text { Result }\end{array}$ & $\begin{array}{c}\text { Kesimpul } \\
\text { an }\end{array}$ & Tampilan Aplikasi \\
\hline Menu Utama & - & $\begin{array}{l}\text { Pelanggan } \\
\text { Baru dan } \\
\text { Pengaduan }\end{array}$ & $\begin{array}{l}\text { Infformasi } \\
\text { Web }\end{array}$ & Berhasil & 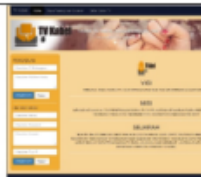 \\
\hline $\begin{array}{l}\text { Pengguna } \\
\text { Login Sebagai } \\
\text { Admin }\end{array}$ & $\begin{array}{l}\text { User: } \\
\text { member } \\
\text { Pass : } 1234\end{array}$ & $\begin{array}{l}\text { Sistem akan } \\
\text { berpindah ke } \\
\text { halaman } \\
\text { tampilan } \\
\text { awwal aplikasi } \\
\text { dasboard } \\
\text { Admin }\end{array}$ & $\begin{array}{l}\text { Sistem } \\
\text { berpindah } \\
\text { ke halaman } \\
\text { tampilan } \\
\text { awal } \\
\text { aplikasi } \\
\text { dasboard } \\
\text { Admin }\end{array}$ & Berhasil & $\mathbf{2}$ \\
\hline $\begin{array}{l}\text { Admin } \\
\text { Mengecek } \\
\text { Pendaftaran } \\
\text { Baru }\end{array}$ & $\begin{array}{l}\text { Kode, } \\
\text { Pelangganl }\end{array}$ & $\begin{array}{l}\text { Sitem akan } \\
\text { menampilka } \\
\text { n data } \\
\text { barang } \\
\text { berhasil } \\
\text { disimpan } \\
\text { pada } \\
\text { database } \\
\text { aplikasi }\end{array}$ & $\begin{array}{l}\text { Sitem } \\
\text { menampilk } \\
\text { an data } \\
\text { Pelanggan } \\
\text { Aktip atau } \\
\text { Tidak }\end{array}$ & Berhasil & 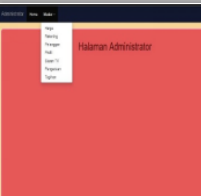 \\
\hline $\begin{array}{l}\text { Admin } \\
\text { Menambah atau } \\
\text { pengurang } \\
\text { Siaran }\end{array}$ & $\begin{array}{l}\text { Penambahan } \\
\text { atau } \\
\text { Penghapusan } \\
\text { Siaran }\end{array}$ & $\begin{array}{l}\text { Data } \\
\text { disimpan } \\
\text { dalam } \\
\text { penambahan } \\
\text { atau } \\
\text { Penghapusan } \\
\text { Penyiaran }\end{array}$ & $\begin{array}{l}\text { Sitem data } \\
\text { barang } \\
\text { dibeli } \\
\text { berhasil } \\
\text { disimpan } \\
\text { pada } \\
\text { database } \\
\end{array}$ & Berhasil & 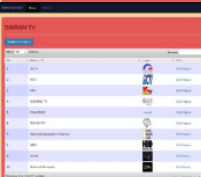 \\
\hline $\begin{array}{l}\text { Admin } \\
\text { membuat } \\
\text { Tagihan }\end{array}$ & $\begin{array}{l}\text { Admin } \\
\text { update } \\
\text { tagihan Baru }\end{array}$ & $\begin{array}{l}\text { Sitem akan } \\
\text { menampilka } \\
\text { n konfirmasi } \\
\text { Tagihan data } \\
\text { disimpan di } \\
\text { database }\end{array}$ & $\begin{array}{l}\text { Sitem } \\
\text { Update ke } \\
\text { tagihan } \\
\text { Pelanggan }\end{array}$ & Berhasil & 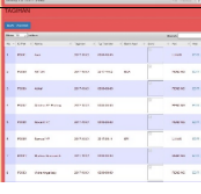 \\
\hline $\begin{array}{l}\text { Member } \\
\text { melihat menu }\end{array}$ & $\begin{array}{l}\text { Member } \\
\text { melihat } \\
\text { tagihan yang } \\
\text { update }\end{array}$ & $\begin{array}{l}\text { Sistem akan } \\
\text { menampilka } \\
\text { n Update } \\
\text { tagihan }\end{array}$ & $\begin{array}{l}\text { Sistem } \\
\text { menampilk } \\
\text { an riwayat } \\
\text { Tagihan }\end{array}$ & Berhasil & 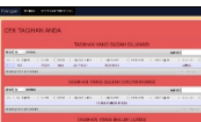 \\
\hline
\end{tabular}

Dari hail pengujian yang telah dilakukan menggunakan testing pengujian black box maka kesimpulan dalah tahap penggunaan aplikasi berjalan dengan baik dan sesuai dengan tujuan yang diinginkan, pengembangan aplikasi ini yang telah diuji coba yang dilakukan secara berkala mulai dari Web Pembuka dan Login masuk Admin dan Pelanggan sudah memenuhi dan layak dipakai sebagai Implementasi dari Aplikasi TV Online. 


\section{KESIMPULAN}

Berdasarkan dari hasil Penerapan Motode Waterfall pada pengembangan aplikasi Pendaftaran TV Online desain Unified Modeling Language (UML) maka dapat ditarik kesimpulan sebagai berikut :

1. Penerapan Metode waterfall dapat memudahkan pengembangan aplikasi dimasa sekarang dan akan datang.

2. Pengembangan Aplikasi Pendaftaran TV Online dapat dilakukan secara online dan sistematis.

3. Penginformasian bisa terintergrasi mulai pendaftaran online, Penagihan dan Pengaduan pelanggan yang tidak terpisah.

Dari kesimpulan yang telah didapat kemudahan dalam Informasi yang didapat mulai dari Chanel yang didapat kemudahan pendaftaran secara online serta keluhan pelanggan dapat diatasi sesegera mungkin karena sudah jadi satu kesatuan yang tidak terpisah dalam satu aplikasi.

\section{DAFTAR PUSTAKA}

[1] E. D. H. \&. M. Widodo, "PENDAFTARAN TV KABEL PADA MNC SKY VISION," Jurnal Visualika, pp. 12-19, $2019 .$.

[2] G. MAHALISA, "WEB DEVELOPER INFORMASI BERBASIS ALGORITMA PEMROGRAMAN," Technologia, pp. 1216, 2020.

[3] N. F. YUSRAN, "Sistem Informasi Pelayanan Pelanggan TV Kabel pada CV. Matahari di Kolaka Utara," PhD Thesis. Universitas Islam Negeri Alauddin Makassar, pp. -, 2017.

[4] J. a. M. A. Maulani, "'RANCANG BANGUN SISTEM INFORMASI JASA PEMBUATAN PAKAIAN DENGAN ALGORITMA PEMPROGRAMAN TERSTRUKTUR."," Technologia: Jurnal Ilmiah, pp. 85-91, 2019.

[5] Maulani, J. (2020). PENERAPAN METODE WATERFALL PADA PENGEMBANGAN APLIKASI SISTEM INFORMASI JASA DAN PENJUALAN DENGAN PEMODELAN BERORIENTASI OBJEK. Technologia: Jurnal Ilmiah, 11(2), 64-70.

[6] S. \&. D. Nidhra, "Black box and white box testing techniques-a literature review," International Journal of Embedded Systems and Applications (IJESA), vol. 2(2), no. IJESA, pp. 29-50., 2012.
[7] R. F. \&. K. Antasari, "Perancangan Aplikasi Mobile Bengkelku Sebagai Informasi Alamat Bengkel Resmi Sepeda Motor Di Kota Yogyakarta Menggunakan GPS Berbasis Android," Data Manajemen dan Teknologi Informasi (DASI), pp. 13(4), 38., 2012.

[8] M. \&. R. Amin, " Implementasi Sistem Aplikasi Soal Ujian Online untuk Sekolah Menengah Pertama (SMP)," SEMINASTIKA, pp. 91-94, 2018.

Jurnal Ilmiah “Technologia" 
Technologia”Vol 11, No. 2, April - Juni 2020

Jurnal Ilmiah "Technologia" 